\title{
Chemical Composition of Volatile Oil from the Roots of Periploca sepium
}

\author{
Mitsuo Mivazawa ${ }^{1 *}$, Tomoko Fujita ${ }^{2}$, Chikako YamafujI ${ }^{1}$, Masahiro Matsui ${ }^{3}$, \\ Nobuo Kasahara ${ }^{2}$, Yutaka TAKAGI ${ }^{2}$ and Yukio IshIKAWA ${ }^{4}$ \\ ${ }^{1}$ Depertment of Applied Chemistry, Faculty of Science and Engineering, Kinki University \\ (Kowakae, Higashiosaka-shi, Osaka 577-8502, JAPAN) \\ ${ }^{2}$ Yutaka Pharmacy Co., Ltd. \\ (Hayashimati, Ogaki, Gifu 503-0015, JAPAN) \\ ${ }^{3}$ World One Co., Ltd. \\ (Hayashimati, Ogaki, Gifu 503-0015, JAPAN) \\ ${ }^{4}$ Laboratory of Applied Entomology, Graduate School of Agriculture and Life Sciences, University of Tokyo \\ (Bunkyo-ku, Tokyo, 113-8657, JAPAN)
}

Edited by J. Sekiya, Kyoto Univ., and accepted May 16, 2004 (received for review April 23, 2004)

\begin{abstract}
Periploca sepium is used in Chinese crude drugs and widely employed as a tonic. The volatiles obtained by steam distillation (yield, $0.10 \%$ ) included 4methoxysalicylaldehyde (87.8\%), furfural $(3.13 \%)$, and lavender lactone $(0.77 \%)$ as the major components.
\end{abstract}

Key words: Periploca sepium, crude drug, volatile oil, 4-methoxysalicylaldehyde, folk medicine

\section{Introduction}

Periploca sepium is listed in the Japanese and Chinese Pharmacopoeia and has been widely used as a tonic. As the original plants of this drug, more than seventeen plants are recorded, most of which belong to Araliaceae, but only one, Periploca sepium BUNGE belongs to Asclepiadaceae (1). A few Asclepiadaceae plants of Indian origin having therapeutic value were reported (2). The volatile components of several Chinese crude drugs have been investigated in our research on flavour compounds or flavour ingredients (3-9). In earlier papers, various glycosides and 4-methoxysalicylaldehyde have been reported from $P$. sepium (10-13), but so far there is no attempt has been made to study the volatile oil from this plant, has not yet been reported. In this report, the chemical composition of volatile oil from the $P$. sepium was investigated.

\section{Experimental}

\section{2·1 Material}

Commercially available air-dried root bark of $P$. sepium was obtained from matsuura kanpo Co., Ltd, (Aichi japan).

\section{$\mathbf{2} \cdot 2$ Isolation of Volatile Oil}

The root bark of P. sepium (200g) was cut into small pieces, hydrodistilled in a Likens-Nickerson type apparatus, with diethyl ether to yield $199 \mathrm{mg}, 0.10 \%$ of essential oil, which was dried over anhydrous sodium sulphate.

\subsection{Gas Chromatography}

GC was carried out using Hewlett-packard 5890 equipped with a flame ionization detector (FID) on a capillary column (DB-5, $30 \mathrm{~m} \times 0.25 \mathrm{~mm}$ i.d.); the

\footnotetext{
*Correspondence to: Mitsuo MiYaZAWA, Department of Applied Chemistry, Faculty of Science and Engineering, Kinki University, Kowakae, Higashiosaka-shi, Osaka 577-8502, JAPAN

E-mail: miyazawa@apch.kindai.ac.jp
} 
column temperature was programmed form $60^{\circ} \mathrm{C}$ to $240^{\circ} \mathrm{C}$ at a rate of $2^{\circ} \mathrm{C} / \mathrm{min}$ and held at $240^{\circ} \mathrm{C}$. The injector and detector temperatures were $270^{\circ} \mathrm{C}$ and $280^{\circ} \mathrm{C}$. The flow rate of the carrier gas $(\mathrm{He})$ was 30 $\mathrm{cm} / \mathrm{sec}$.

\subsection{Gas-Liquid Chromatography-Mass Spectrometry (GC-MS)}

GC-MS was carried out with a Hewlett-Packard 5972 instrument. GC conditions were the same as previously described. The detector interface temperature in the MS source reaching approximaterly $180^{\circ} \mathrm{C}$ and the ionization voltage $70 \mathrm{eV}$. Capillary $\mathrm{GC}$ was operated in the computer library and verified by comparison of mass spectra and literature data, and confirmed by GC analyses of authentic samples from previous work (39).

\section{Results and Discussion}

Hydrodistillation gave $0.10 \%(\mathrm{w} / \mathrm{w})$ essential oil. A gas chromatogram of the volatile oil of $P$. sepium is shown in Fig. 1, from which 57 components were separated. As shown in Table 1, 57 components of oils were identified by direct comparison with authentic samples on the basis of retention time and GC-MS and confirmed by analyses of authentic samples from our previous work (3-9). Around $90 \%$ of the volatile oil was accounted for by a single aromatic principle, viz. 4methoxysalicylaldehyde, which readily crystallized out as fine needles. Thus identified compounds relative peak area percentages are give in Table $\mathbf{1}$.

The major constituents were aromatic, which were 4methoxysalicylaldehyde $(87.99 \%), p$-anisaldehyde $(0.17 \%)$, cinnamaldehyde $(0.32 \%)$, eugenol $(0.39 \%)$, 2hydroxy-4-methoxy-acetophenone $(0.25 \%)$, and anethole $(0.22 \%)$. The total content of aromatic compounds in the volatile oil was $89.34 \%$.

\section{References}

1. J. SHOJI, S. KAWANISHI, S. SAKUMA and S. SHIBATA, Studies on the Chemical Constituents of Chinese Drug "Wujiapi”, Chem. Pharm. Bull., Vol. 15, 720-723 (1967).

2. S. NAGARJAN, L. JAGANA, MOHAN RAO and K.N. GURUDUTT, Chemical Composition of the Volatiles of Decalepis hamiltonii (Wight \& Arn), Flavour Fragr. J., Vol. 16, 27-29 (2001).

3. M. MIYAZAWA, Y. MINAMINO and H. KAMEOKA, Volatile Flavor Components of Crude Drugs. Part IX, Volatile Components of the Rhizomes of Pheum palmatum L, J. Essent. Oil Res., Vol. 11, 57-60 (1996).

4. M. MIYAZAWA, Y. MINAMINO and H. KAMEOKA, Volatile Components of Ephedra sinica Stapf., Flavour Fragr. J., Vol. 12, 15-17 (1997).

5. M. MIYAZAWA, Y. MINAMINO and H. KAMEOKA, The Essential Oil of Erigeron canadensis L., Flavour Fragr. J., Vol. 4, 227-230 (1997).

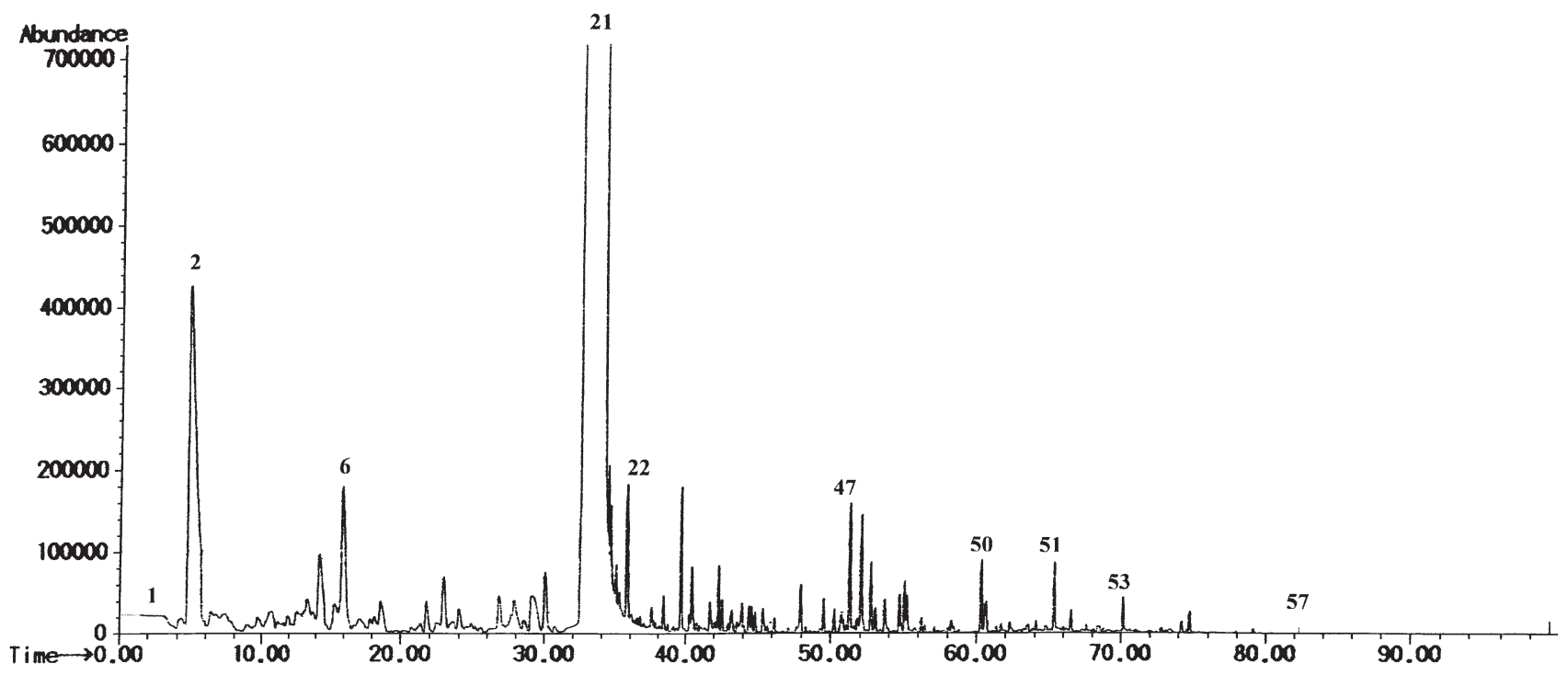

Fig. 1 Gas Chromatogram of the Essential Oil from the Root Bark of P. sepium Column, DB-5 (30m $\times 0.25 \mathrm{~mm}$ i.d.); flow rate of the carrier gas, $30 \mathrm{~cm} / \mathrm{sec}$; oven temperature: $60-240{ }^{\circ} \mathrm{C}$ at $2{ }^{\circ} \mathrm{C} / \mathrm{min}$, Injector temperature: $270^{\circ} \mathrm{C}$, Detector temperature: $280^{\circ} \mathrm{C}$ 
Table 1 Chemical Composition of the Volatiles from the Root of $P$. sepium.

\begin{tabular}{|c|c|c|c|c|c|c|c|}
\hline No. & $\mathrm{RI}^{\mathrm{a}}$ & compound $^{\mathrm{b}}$ & peak area $(\%)$ & No. & $\mathrm{RI}^{\mathrm{a}}$ & compound $^{\mathrm{b}}$ & peak area $(\%)$ \\
\hline 1 & 800 & hexanal & $\operatorname{tr} *$ & 30 & 1443 & vanillin & 0.03 \\
\hline 2 & 830 & furfural & 3.13 & 31 & 1446 & geranyl acetone & 0.11 \\
\hline 3 & 982 & 2-pentyl furan & 0.01 & 32 & 1448 & $\alpha$-humulene & 0.02 \\
\hline 4 & 1031 & limonene & 0.17 & 33 & 1452 & (Z)-methyl isoeugenol & 0.02 \\
\hline 5 & 1060 & 2-acetylpyrrole & 0.09 & 34 & 1477 & ar-curcumene & 0.11 \\
\hline 6 & 1071 & lavender lactone & 0.77 & 35 & 1481 & $\beta$-selinene & 0.06 \\
\hline 7 & 1098 & linalool & 0.04 & 36 & 1488 & $\alpha$-selinene & 0.02 \\
\hline 8 & 1152 & menthone & 0.03 & 37 & 1492 & $\alpha$-muurolene & 0.06 \\
\hline 9 & 1158 & nonanol & 0.12 & 38 & 1503 & $\beta$-bisabolene & 0.06 \\
\hline 10 & 1176 & terpinen-4-ol & 0.20 & 39 & 1512 & $\delta$-cadinene & 0.05 \\
\hline 11 & 1192 & $\alpha$-terpineol & 0.03 & 40 & 1515 & trans-calamenene & 0.04 \\
\hline 12 & 1205 & (4Z)-decenal & $\operatorname{tr}^{*}$ & 41 & 1534 & $\alpha$-calacolene & 0.01 \\
\hline 13 & 1209 & myrtenal & $\operatorname{tr} *$ & 42 & 1542 & elemol & 0.03 \\
\hline 14 & 1215 & $(2 Z, 4 Z)$-nonadienal & $\operatorname{tr*}$ & 43 & 1558 & geranyl $n$-butyrate & 0.01 \\
\hline 15 & 1216 & trans-carveol & $\operatorname{tr} *$ & 44 & 1573 & caryophyllene oxide & 0.10 \\
\hline 16 & 1234 & pulegone & 0.10 & 45 & 1600 & hexadecane & 0.05 \\
\hline 17 & 1249 & $p$-anis aldehyde & 0.17 & 46 & 1631 & hinesol & 0.22 \\
\hline 18 & 1268 & (E)-cinnamaldehyde & 0.32 & 47 & 1645 & $\beta$-eudesmol & 0.23 \\
\hline 19 & 1283 & $(E)$-anethole & 0.22 & 48 & 1658 & ar-turmerone & 0.11 \\
\hline 20 & 1292 & 2-undecanone & 0.00 & 49 & 1700 & heptadecane & 0.08 \\
\hline 21 & 1338 & 4-methoxy-salicyl aldehyde & 87.99 & 50 & 1800 & octadecane & 0.12 \\
\hline 22 & 1353 & eugenol & 0.39 & 51 & 1900 & nonadecane & 0.11 \\
\hline 23 & 1360 & $\gamma$-nonalactone & 0.09 & 52 & 1924 & methyl palmitate & 0.03 \\
\hline 24 & 1382 & $\alpha$-isocomene & 0.03 & 53 & 2000 & eicosane & 0.06 \\
\hline 25 & 1386 & $\beta$-elemene & 0.04 & 54 & 2088 & methyl linoleate & 0.02 \\
\hline 26 & 1399 & methyl eugenol & 0.05 & 55 & 2100 & heneicosane & 0.04 \\
\hline 27 & 1413 & $\beta$-caryophyllene & 0.07 & 56 & 2123 & linoleic acid & 0.07 \\
\hline 28 & 1418 & $\alpha$-ionone & 0.01 & 57 & 2200 & docosane & 0.01 \\
\hline 29 & 1433 & 2-hydroxy-4-methoxy-acetophenone & 0.01 & & & & \\
\hline
\end{tabular}

${ }^{a}$ Retention index on TC-WAX.

${ }^{\mathrm{b}}$ All components were identified by comparing retention times of GLC and MS with authentic samples.

$*$ trace $<0.01 \%$

6. M. MIYAZAWA, Y. MINAMINO and H. KAMEOKA, Volatile Components of the Rhizomes of Dioscorea japonica, Flavour Fragr. J., Vol. 9, 245-248 (1997).

7. M. MIYAZAWA, S. OKAMURA, Y. OKUNO and S. MORII, Components of the Essential Oil of Cryptotanenia japonica Hassk "itomitsuba" for Japanese Food, Flavour Fragr. J., Vol. 14, 273-275 (1999).

8. M. MIYAZAWA, K. KUROSE, A. ITOH, N. HIROOKA and H. KAMEOKA, Components of the Essential Oil from Glehnia littoralis, Flavour Fragr. J., Vol. 16, 215-218 (2001).

9. M. MIYAZAWA, K. KUROSE, A. ITOH and N. HIRAOKA, Comparison of the Essential Oils of Glehnia littoralis from Northern and Southern Japan, J. Agric. Food. Chem., Vol. 49, 5433-5436 (2001).

10. LU GUIBAO and ZHANG MINHE, Determination of 4- methoxysalicylaldehyde by HPLC in Chinese silkvine (Periploca sepium), Zhongcaoyao, Vol. 19, 16-18 (1988).

11. HUANG QING, ZHANG HONGYAN, LI YONGEN CHENG GUANGYU, ZHANG BEN and XI HONGSHAN, Determination of 4-methoxysalicylic Aldehyde in the Periploca sepium Bge. Bark or Root by Thin Layer Chromatogram Scanner, Fenxi Huaxue, Vol. 23, 236 (1995).

12. Y. OSHIMA, T. HIROTA, H. HIKINO, Periplosides A, B and C, Steroidal Glycosides of Periploca sepium Root Barks, Heterocycles, Vol. 26, 2093-2098 (1987).

13. H. ITOKAWA, J. XU and K. TAKEYA, Studies on Chemical Constituents of Antitumor Fraction from Periploca sepium. V. Structures of New Pregnane Glycosides, Periplocosides J, K, F and O, Chem. Pharm. Bull. Vol. 11, 4441-4446 (1988). 